University of Nebraska - Lincoln

DigitalCommons@University of Nebraska - Lincoln

Management Department Faculty Publications

Management Department

2010

\title{
What Do Conscientious People Do? Development and Validation of the Behavioral Indicators of Conscientiousness (BIC)
}

Joshua J. Jackson

University of Illinois at Urbana-Champaign, jjackso7@illinois.edu

Dustin Wood

Wake Forest University

Tim Bogg

Indiana University - Bloomington

Kate E. Walton

St. John's University - New York

Peter D. Harms

University of Nebraska - Lincoln, pharms@gmail.com

See next page for additional authors

Follow this and additional works at: https://digitalcommons.unl.edu/managementfacpub

Part of the Management Sciences and Quantitative Methods Commons

Jackson, Joshua J.; Wood, Dustin; Bogg, Tim; Walton, Kate E.; Harms, Peter D.; and Roberts, Brent W., "What Do Conscientious People Do? Development and Validation of the Behavioral Indicators of Conscientiousness (BIC)" (2010). Management Department Faculty Publications. 79.

https://digitalcommons.unl.edu/managementfacpub/79

This Article is brought to you for free and open access by the Management Department at DigitalCommons@University of Nebraska - Lincoln. It has been accepted for inclusion in Management Department Faculty Publications by an authorized administrator of DigitalCommons@University of Nebraska - Lincoln. 


\section{Authors}

Joshua J. Jackson, Dustin Wood, Tim Bogg, Kate E. Walton, Peter D. Harms, and Brent W. Roberts 


\title{
What Do Conscientious People Do? Development and Validation of the Behavioral Indicators of Conscientiousness (BIC)
}

\author{
Joshua J. Jackson ${ }^{\mathrm{a},}{ }^{,}$, Dustin Wood ${ }^{\mathrm{b}}$, Tim Bogg ${ }^{\mathrm{c}}$, Kate E. Walton ${ }^{\mathrm{d}}$, Peter D. Harms ${ }^{\mathrm{e}}$, Brent W. Roberts ${ }^{\mathrm{a}}$ \\ aDepartment of Psychology, University of Illinois, Urbana-Champaign, Champaign, Illnois, USA, jjackso7@illinois.edu \\ ${ }^{b}$ Department of Psychology, Wake Forest University, Winston-Salem, North Carolina, USA \\ 'Department of Psychological and Brain Sciences, Indiana University, Bloomington, Indiana, USA \\ dDepartment of Psychology, St. John's University, Queens, New York, USA \\ eDepartment of Management, University of Nebraska-Lincoln, Lincoln, Nebraska, USA, pdharms2@unl.edu
}

Article available online June 17, 2010.

Keywords: Conscientiousness; Behavior; Personality; Trait; Facet

Abstract

Typical assessments of personality traits collapse behaviors, thoughts, and feelings into a single measure without distinguishing between these different manifestations. To address this lack of specification, the current study develops and validates a measure that assesses a number of broad behaviors associated with the personality trait of conscientiousness (the Behavioral Indicators of Conscientiousness; BIC). Findings suggest that the lower-order structure of conscientious behaviors is mostly similar to the lower-order structure in extant trait measures. Furthermore, a daily diary method was used to validate the BIC against frequency counts of conscientious behavior. Overall, the results identify specific behaviors that conscientious individuals tend to perform and highlight possible advantages of this approach over broad trait assessment.

\section{Introduction}

The study of behavior is integral to the field of personality psychology (Furr, 2009). The importance of behavior in personality is even more apparent when considering the multitude of theories that rely on behavior to explain the mediation of psychological processes (e.g., how personality leads to job performance or relationship satisfaction) or that conceptualizes behavior as important manifestations of our underlying feelings and desires (Furr, 2009). Whether a researcher is interested in underlying mechanisms or concrete outcomes, behavior plays a role. Given the importance of behavior, it is reasonable as a science to document a list of behaviors that are associated with the major constructs that are the focus of scientific research (Funder, 2009). Despite the importance of behavior to the conceptualization of personality, personality psychology has failed to pay a proportionate amount of attention to the study of behavior (Fleeson, 2007; Furr \& Funder, 2007; Wu \& Clark, 2003). For example, only a small number of behaviors have been identified for the major trait dimensions of personality (Funder, 2001, 2006), despite each of these traits being associated with important life outcomes (Ozer \& Benet-Martínez, 2006; Roberts et al., 2007).

The lack of the identi.cation of specific behaviors associated with particular personality traits is even more unfortunate considering that personality traits are assessed, partially, by behavior and, therefore, defined in part by behavior (Werner \& Pervin, 1986). Personality traits, however, are not just summaries of behavior. Rather, personality traits are typically defined as the relatively enduring patterns of thoughts, feelings, and behaviors that are manifest in trait-affording situations (Roberts \& Jackson, 2008; Tellegen, 1991). Tradi- tional measures of personality include all of these typesthoughts, feeling and behaviors - of personality manifestations (Pytlik Zillig, Hemenover, \& Dienstbier, 2002; Werner $\&$ Pervin, 1986). From this view, behavior is only one part of what constitutes a personality trait. Thus far, personality traits are defined and researched only as the combination of these types of manifestations without an objective organization of trait dimensions into cognitive, affective, and behavioral components. As such, studying the behavioral components of a personality trait in isolation of other components may offer advantages over examining thoughts, feelings and behaviors simultaneously in the same questionnaire.

The goal of the present research is to answer the question, "what does a conscientious person do?" by documenting behaviors associated with conscientiousness. Conscientiousness is defined as individual differences in the propensity to follow socially prescribed norms for impulse control, to be goal-directed, planful, able to delay gratification, and to follow norms and rules (Roberts, Jackson, Fayard, Edmonds, \& Meints, 2009). The breadth of this definition implicates a wide swath of important outcomes that are associated with conscientiousness. Indeed, conscientiousness is associated with better health, lower criminal activity, and better economic, interpersonal, and workplace outcomes (Roberts et al., 2009, chapter 25).

Uncovering the behavioral manifestations of conscientiousness is important for several reasons. First, it will increase our understanding of the trait itself, as it may clarify or enhance the spectrum of underlying facets that make up the domain of conscientiousness. Second, it affords alternative ways of assessing the trait. For example, behaviors can be thought of as state manifestations of a personality trait and 
can therefore better characterize variability in personality. Moreover, specific conscientious behaviors may help clarify why conscientiousness is associated with living longer and greater career success (Judge, Higgins, Thoresen, \& Barrick, 1999; Kern \& Friedman, 2008), as it may have to do with specific actions they take rather than attitudes or feelings they possess.

\section{Behavior and Personality}

The Act Frequency Approach (AFA; Buss \& Craik, 1980) is the most elaborate system to study behaviors to date, and it is necessary to discuss the AFA in order to distinguish it from the approach used in the present research. In the AFA, personality dispositions were defined by the frequency of acts that belonged to dispositional categories. For example, to be dominant one must perform a significant number of dominant acts over a certain time frame. It was reasoned that if a person behaved in such a manner in the past they then would behave similarly in the future (Buss \& Craik, 1983).

A number of the assumptions and procedures that formed the basis of the AFA were criticized (Block, 1989), which subsequently caused the AFA, and arguably the study of personality and behavior, to fall out of favor. These criticisms have taken two forms. The first pertained to the lack of methodological and psychometric rigor in the initial efforts to validate the AFA. The second critique was more theoretical and dealt with the implications of viewing dispositions (i.e., traits) solely as summaries of behaviors and not explanatory concepts (Funder, 1991). Acts were used to define a particular disposition and this disposition was then used to predict future acts. This reasoning is circular and provides no power of explanation because it relies on past behaviors to predict future behaviors (Block, 1989). The AFA approach therefore leaves out psychological processes that are mostly unobservable, such as emotions, motives, goals, and interests.

Alternatively, Neo-Allportian (Funder, 1991) and Sociogenomic (Roberts \& Jackson, 2008) models of personality traits propose that a trait is made up of thoughts, feelings, and behaviors. In these models, behavior can be either the result of thoughts and feelings or simply one component used to define a trait. In either case, behavior is an important component of a trait but not sufficient to define a trait and should not be equated with personality traits. Therefore, studying the behaviors associated with a trait would represent a start on cataloging one component of what comprises a personality trait. Moreover, it would allow researchers to tease apart the relations among trait-relevant thoughts, feelings, and behaviors to the extent that one goes onto identify and de.ne the relevant thoughts and feeling components of a personality trait. Despite the shortcomings, the ambitious AFA and AFA-related offshoots yielded a number of promising results, both theoretically and empirically. A number of studies examined whether behavioral acts can be identi.ed and reliably reported. Inter-judge agreement for molecular behaviors is high across a number of traits suggesting that lay judges realize (and agree) that certain behaviors re.ect particular dispositions (Borkenau \& Muller, 1992; Borkenau \& Ostendorf, 1987; Funder \& Sneed, 1993). Similarly, the behaviors that comprise these dispositional categories are correlated within a person (Buss \& Craik, 1983). Moreover, people are able to accurately report their past behaviors (Borkenau \& Ostendorf, 1987; Gosling, John, Craik, \& Robins, 1998; Vazire \& Mehl, 2008). For example, Gosling et al. (1998) found that retrospective reports of conscientious behaviors correlated around .45 with a judge's online report of behavior. Interestingly, these retrospective behavioral reports focused on speci.c types of utterances and directions rather than behaviors lasting more than a few seconds. These findings may underestimate the ability to recall behaviors that last longer and are not entirely verbal, which would lead to even more accurate retrospective reports of behavior. Moreover, the estimates in the study by Gosling et al. (1998) study were based on single behaviors. Act trends, using the original AFA terminology, or behavioral factors comprising multiple related behaviors, would provide better psychometric properties and likely yield higher levels of overlap (Epstein, 1979).

Recent studies have started to link the vast number of behaviors people perform everyday to personality traits (e.g., Asendorpf, Banse, \& Mücke, 2002; Back, Schmukle, \& Egloff, 2006; Borkenau, Mauer, Riemann, Spinath, \& Angleitner, 2004; Church et al., 2007; Fast \& Funder, 2008; Heller, Komar, \& Lee, 2007; Hong, Paunonen, \& Slade, 2008; Markey, Markey, \& Tinsley, 2004; Mehl, Gosling, \& Pennebaker, 2006; Nave, Sherman, \& Funder, 2008; Paunonen, 2003; Spain, Eaton, \& Funder, 2000; Wu \& Clark, 2003). These studies identified a number of behaviors associated with the trait of conscientiousness, such as finishing a task on time, arriving to a meeting on time, having a slouching body posture, and skipping responsibilities on a whim (Back, Schmukle, \& Egloff, 2009; Church et al., 2007).

Despite the research on or inspired by the AFA, the breadth and scope of behaviors related to speci.c trait domains, such as conscientiousness, are not known. Previous research focused on behaviors in a small number of situations, such a laboratory settings, thus limiting the scope of the behaviors examined. Furthermore, a similar narrow focus also characterizes research that has studied behaviors from outside of the lab. In contrast, no study has attempted to catalog a comprehensive sample of behaviors associated with conscientiousness.

\section{The Present Research}

The present research builds upon the research legacy of the AFA to identify the behaviors associated with the personality trait of conscientiousness, answering the question of, "what do conscientious people do?" In three studies we identify behaviors that represent the concrete activities exhibited in people's day-to-day lives that are relevant to the trait of conscientiousness to create a measure of conscientious behaviors (Behavioral Indicators of Conscientiousness; BIC). In doing so, we examined the factor structure of conscientious behaviors to identify the hierarchical structure of conscientious behaviors, the convergent and divergent validity of the behavioral scales and finally we validated the measure using a daily diary study.

Conscientiousness is a broad domain of traits that subsumes multiple lower order facets. Presently, at least five facets can be thought of as components of conscientiousness: industriousness, orderliness, impulse control, reliability, and conventionality (Jackson et al., 2009; Roberts, Chernyshen- 
ko, Stark, \& Goldberg, 2005; Roberts et al., 2004). Additional facets may also be part of conscientiousness such as virtue and decisiveness (Hough \& Ones, 2001; Roberts et al., 2005) but have yet to be confirmed in subsequent research. Fewer numbers of conscientiousness facets also have been proposed (DeYoung, Quilty, \& Peterson, 2007; Paunonen \& Jackson, 1996).

The range in the number of facets highlights that personality traits are structured hierarchically, with the assumption that no one level of analysis is correct (Goldberg, 2006; Markon, Krueger, \& Watson, 2005; Tackett, Quilty, Sellbom, Rector, \& Bagby, 2008). Likewise, behaviors can be structured hierarchically and represent specific, lower order manifestations of conscientiousness. Looking at behaviors offers another way to examine the lower-order structure of conscientiousness and whether or not the structure replicates across methods of assessment. For example, the Big Five does not necessarily emerge when just behavioral items are factor analyzed into a five-factor space (Botwin \& Buss, 1989). It is unknown how closely conscientious behaviors will resemble the structure of conscientiousness based on questionnaires or adjective measures. Additionally, because the facets of conscientiousness identified in past studies were based on extant questionnaires and adjective measures, the breadth and number of facets that emerged are possibly limited. Behaviors, in contrast, may cast a wider net and identify new facets that are important for conscientiousness but heretofore missed by other methods.

Study 1: Behavioral Indicators of Conscientiousness Scale Development

We first set out to document a large set of behaviors that are associated with conscientiousness. We then examined these behaviors hierarchically to compare the structure of behaviors with the structure of conscientiousness questionnaires. Examining behaviors hierarchically allows behavior to be conceptualized as either broad behavioral factors, such as self-control, which subsumes many different behaviors, or, alternatively, at a lower level that focuses on specific behaviors such as impulsive spending. The hierarchical approach is ideal for researchers who may have different assessment needs and a desire to measure the concepts at more general or more specific levels of analysis.

\section{Method}

\section{Participants and Procedure}

Item content was generated from three populations. First, several dozen students participating in ongoing research studies were given a definition of conscientiousness (John \& Srivastava, 1999) and asked to write down as many behaviors as they could that they associated with the definition. Second, the same instructions were provided to a small sample of adults from the community surrounding the university taking part in a pilot study on conscientiousness and health (Lodi-Smith et al., 2010). Third, a team of graduate and undergraduate research assistants were asked to list as many behaviors as possible that they associated with the dimensions of conscientiousness identified in the literature (Peabody and De Raad, 2002; Roberts et al., 2004, 2005;
Saucier and Ostendorf, 1999; see also Furr (2009) for a discussion of various definitions of behavior as applied to personality psychology). To diminish potential overlap with outcomes in our ongoing research linking conscientiousness to health (e.g., Lodi-Smith et al., 2010), all behaviors thought to be related to health, ranging from brushing teeth to exercising, were eliminated.

Next, graduate research assistants made two prototypicality ratings for every item. Each expert first rated the prototypicality of the behavior for the each of the Big Five factors. Items were discarded if conscientiousness was not the most prototypical trait. Experts then rated the prototypicality for each item for nine different facets of conscientiousness found in the literature (Peabody \& De Raad, 2002; Roberts et al., 2004, 2005). Facets that did not have an extensive list of items associated with them were then filled out with additional items. This procedure resulted in an initial item pool of 511 items.

Next, the item pool went through three iterative waves of data collection. Across the three waves, questionnaires were collected from a total $N=1,359$ participants (41\% male). Participants were college students who participated for class credit. Participants were asked to indicate how often they took part in each behavior on a 1-5 scale, with responses ranging from "never performed the behavior" to "performing the behavior quite often." Items were dropped from wave to wave if the behavior did not correlate with measures of conscientiousness. This resulted in an item pool of 199 items for wave 2. The wording was modi.ed for eight items after the first wave of data collection because the base rate of behavior was too low (e.g., "iron underwear" was changed to "fold underwear"). This slight revision of item wording increased the base rate for four of the eight items during wave 2 . The total $N$ for these items is 1,128 . Items that did not have adequate base rates and that did not significantly correlate with conscientious facets as measured by the AB5C (Goldberg (1999)) and the CAC (Jackson et al., 2009) were dropped from the item pool. The final round left us with 185 behavioral-items that both met the characteristics of being highly related to at least one facet of conscientiousness and were not too rare. These behaviors (Appendix A) constitute the Behavioral Indicators of Conscientiousness (BIC).

\section{Analyses}

Structural analyses were performed with the goal of exploring different levels in the hierarchy of conscientious behaviors, rather than identifying the single best .tting or most parsimonious factor structure (Goldberg, 2006). We did this for three reasons. First, we desired to test whether the hierarchical structure found in conscientiousness questionnaires (Roberts et al., 2005) replicated at a behavioral level. Secondly, this analysis provided a more complete, hierarchical picture of the structure of conscientiousness acts. This hierarchical structure can be useful to researchers who may face varying assessment demands, such as needing a brief, broad measure (higher level of the hierarchy), a brief, specific measure (single facet at the lower level of the hierarchy), or a comprehensive assessment (multiple facets at the lower level of the hierarchy). Third, this approach is better suited to differentiate the relationship between conscientiousness and outcomes associated with it (for an example of this approach applied to psychopathology, see Tackett et al. (2008)). 


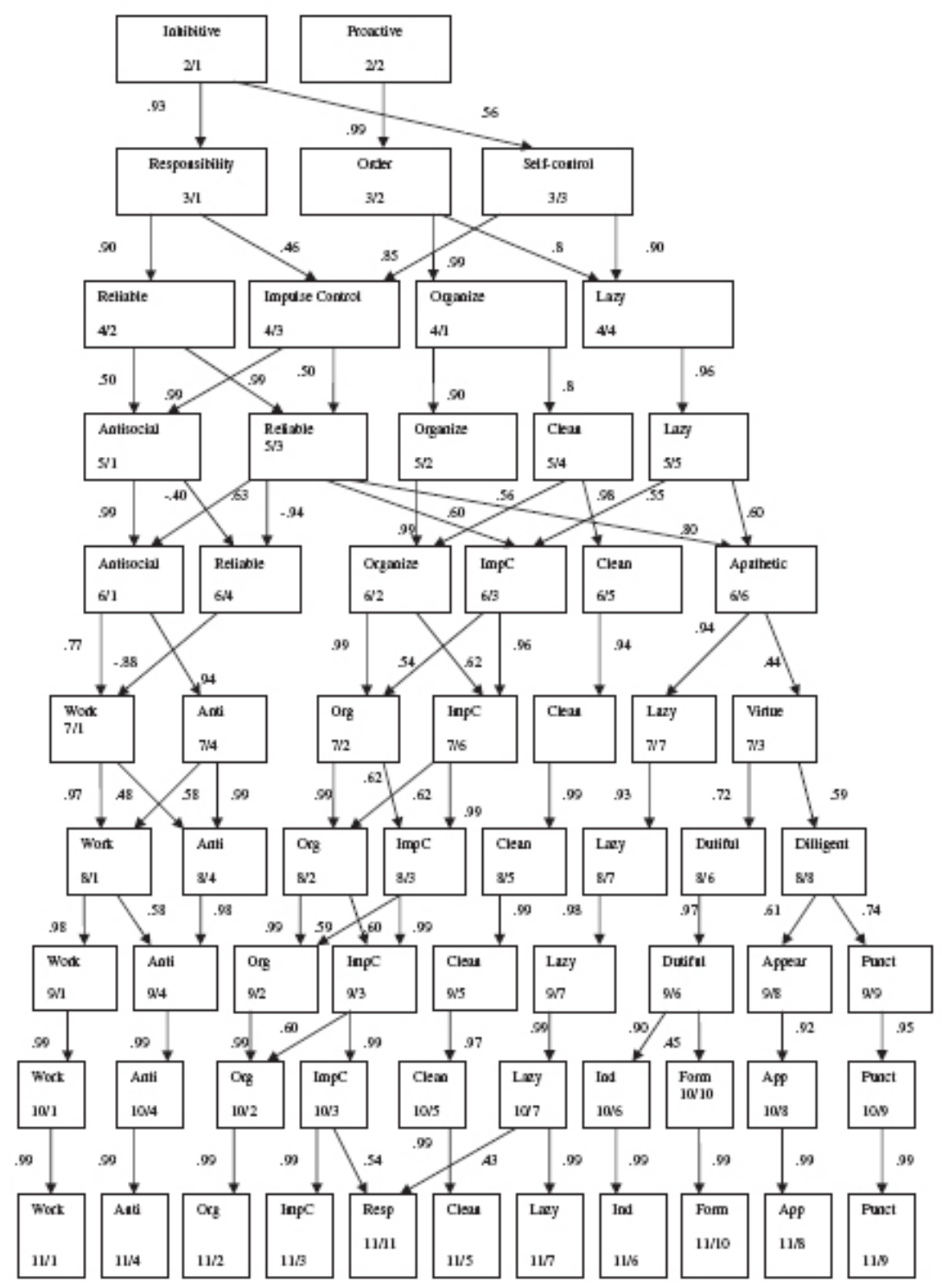

Figure 1. Hierarchy of conscientious behaviors.

Items were subjected to principal axis factor analysis with oblique rotation using maximum likelihood estimation. To construct a hierarchy of conscientious behaviors, we employed a top-down approach where a principal factor was first extracted, then two factors were extracted and rotated, then three were extracted, and so on (Goldberg, 2006). Subsequent numbers of factors were extracted until interpretable factors failed to emerge. Additionally, we overextracted the factor solutions to ensure the factor solutions were stable. Factor scores were saved for each analysis, and the loadings between each level of the hierarchy were calculated by correlating factor scores with one another.

\section{Results and Discussion}

To investigate the structure of conscientious behaviors we conducted a series of exploratory factor analyses of increasing complexity and differentiation. The resulting conscientious behavior hierarchy was interpretable up to 11 factors (see Figure 1). At the lowest level of the hierarchy the 11 re- sulting behavioral factors were: avoid work (e.g., blow off work), organization (e.g., use a planner to schedule events), impulsivity (e.g., buy something on a whim), antisocial (e.g., litter), cleanliness (e.g., clean the bathroom), industriousness (e.g., work long hours), laziness (e.g., sitting and doing nothing), appearance (e.g., make my bed), punctuality (e.g., got to an appointment on time), formality (e.g., call someone Ms., Mr., Mrs., Sir), and responsibility (e.g., break a promise). Correlations among the 11 behavioral factors ranged from 0 to .53 (see Table 1). The alpha reliabilities of the scales were good, averaging .79, with a range of .65-.91.

The top of the hierarchy resembles conscientious hierarchies found using questionnaire items or adjectives (Hough \& Ones, 2001; Roberts et al., 2004, 2005). The two-factor solution consisted of a proactive and inhibitive behavior factor, representing behaviors that re.ect controlled effort toward a goal state (e.g., clean the bathroom) versus behaviors reflecting the control of impulses (e.g., purchase something spon taneously; Costa, McCrae, and Dye, 1991). This is in contrast 
Table 1

Correlations among behavioral factor

\begin{tabular}{|c|c|c|c|c|c|c|c|c|c|c|}
\hline Factor 1 Avoid work & F1 & F2 & F3 & F4 & F5 & F6 & F7 & F8 & F9 & F10 \\
\hline Factor 2 Organization & -.03 & & & & & & & & & \\
\hline Factor 3 Impulsivity & $.25^{*}$ & $-.09^{*}$ & & & & & & & & \\
\hline Factor 4 Antisocial & $.49^{*}$ & $-.20^{*}$ & $.32^{*}$ & & & & & & & \\
\hline Factor 5 Cleanliness & $-.12^{*}$ & .48 & -.03 & -.04 & & & & & & \\
\hline Factor 6 Industriousness & $-.16^{*}$ & $.48^{*}$ & $-.08^{*}$ & $-.22^{*}$ & $.35^{*}$ & & & & & \\
\hline Factor 7 Laziness & $.38^{*}$ & $-.22^{*}$ & $.32^{*}$ & $.36^{*}$ & $-.21^{*}$ & $-.28^{*}$ & & & & \\
\hline Factor 8 Appearance & $-.32^{*}$ & $.53^{*}$ & $-.13^{*}$ & $-.41^{*}$ & $.45^{*}$ & $.44^{*}$ & $-.37^{*}$ & & & \\
\hline Factor 9 Punctuality & $-.53^{*}$ & $.29^{*}$ & $-.20^{*}$ & $-.36^{*}$ & $.13^{*}$ & $.38^{*}$ & $-.42^{*}$ & $.48^{*}$ & & \\
\hline Factor 10 Formality & $-.12^{*}$ & $.39^{*}$ & -.04 & $-.23^{*}$ & $.38^{*}$ & $.36^{*}$ & $-.26^{*}$ & $.43^{*}$ & $.31^{*}$ & \\
\hline $\begin{array}{l}\text { Factor } 11 \text { Responsibility } \\
N=1,128-1,359\end{array}$ & $-.35^{*}$ & $.13^{*}$ & .00 & $-.35^{*}$ & .05 & $.27^{*}$ & $-.17^{*}$ & $.39^{*}$ & $.43^{*}$ & $.25^{*}$ \\
\hline
\end{tabular}

to a recently proposed two-factor solution consisting of industriousness and orderliness (DeYoung et al., 2007), which mostly assesses the proactive components of conscientiousness (Roberts et al., 2005). In the three-factor solution, the factor representing the control of impulses differentiated into two factors representing responsibility (e.g., miss an appointment) and impulse control (e.g., said something I later regretted). The proactive factor remained similar to the twofactor solution and consisted of behaviors associated with orderliness and industriousness (e.g., used a planner to schedule the day's events).

A notable absence is the facet industriousness as one of the three main facets of conscientiousness (DeYoung et al., 2007; Paunonen \& Jackson, 1996). In our solution, behaviors associated with orderliness mainly characterized the proactive factor in the three-factor solution, with industrious behaviors loading less strongly. Not until the four-factor solution did something akin to industriousness emerge. The laziness factor at the four-factor solution encompasses many of the key components of achievement or industriousness (e.g., Persist at tasks after a failure; Work extra hard on a project to make sure that it is done right), though it is slightly broader in scope (e.g., Watched TV or went on the internet instead of taking care of responsibilities, Left dirty clothes on the floor) that suggest that industriousness carries over into non-achievement contexts. These results replicated past findings across a number of studies that suggest responsibility, order, industriousness, and self-control are four critical facets of conscientiousness (Peabody and De Raad (2002), Perugini and Gallucci (1997), Roberts et al. (2004, 2005), Saucier and Ostendorf (1999); see Appendix A for the items associated with the four-factor solution).

Beyond the four-factor solution, the behavioral hierarchy differs from past conscientious hierarchies. From the fivefactor solution beyond, each additional level produces a new factor, mostly derived from a single higher-level factor. For example, cleanliness emerged at the five-factor solution, splitting the orderliness factor into cleanliness and organization. An appearance factor (similar to tidiness in MacCann, Duckworth, and Roberts (2009)) emerged later from a separate factor, the laziness factor. Despite both factors appearing to ostensibly measure cleaning behaviors (e.g., cleaning microwave versus throwing trash away), the two factors are only moderately correlated $(r=.45)$ and appear to be brought on by different motivations. The cleanliness factor mostly consists of germ freeing practices (e.g., cleaning the toilet), whereas the appearance items are focused not on sanitary conditions but on a desire to be orderly and non-cluttered (e.g., having a clean desk surface).

At the lowest level of analysis most of the previously identified facets of conscientiousness emerge, such as punctuality and formality (MacCann et al., 2009; Roberts et al., 2004). These lower level facets often fail to emerge in traditional factor structure studies because of the limited number of adjectives that tap these domains and the greater likelihood for items to be contextualized. The lower level of analysis can be quite informative, as it likely to have greater predict validity than a broader trait assessment. In contrast, the broad factors closer to the top level of the hierarchy (i.e., the fourfactor solution) are likely to predict a broader range of outcomes. The hierarchal structure of conscientious behaviors identified here offers a vivid snapshot of what conscientious people are like in their day-to-day activities, while providing multiple levels of analyses to assess these behaviors.

\section{Study 2: Convergent and Discriminant Validity}

Method

Participants

Participants were recruited from undergraduate classes at a large Midwestern university who participated in return for class credit. The number of participants ranged from 484 to 841 depending on the scale used. The majority of the total sample was women $(63 \%)$, with an average age of 20.2 .

\section{Measures}

To assess the overlap between the 11 behavioral factors and existing conscientiousness scales, the BIC was administered along with the 452-item Abridged Big-Five Circumplex (AB5C; Goldberg, 1999) and the Conscientiousness Adjective Checklist (CAC; Jackson et al., 2009). These questionnaires were chosen because each has a number of facet scales thought to tap conscientiousness. To date, five replicable facets of conscientiousness have been identified: industriousness, orderliness, impulse control, responsibility, and conventionality (Jackson et al., 2009; Roberts et al., 2004). The AB5C consists of nine scales and mainly assesses the industriousness and orderliness facets of conscientiousness, with a single scale, cautiousness, that taps the impul sivity facet (Roberts et al., 2005). The CAC consists of five scales that were developed to assess the five replicable facets of conscientious- 
Table 2

Correlations with BIC and Big Five

\begin{tabular}{|c|c|c|c|c|c|c|}
\hline & $\mathrm{C}(\mathrm{AB} 5 \mathrm{C})$ & $\mathrm{C}(\mathrm{CAC})$ & Agreeableness & Extraversion & Emotional stability & Openness \\
\hline BIC & .73 & .68 & .38 & .24 & .06 & .21 \\
\hline Avoid Work & -.47 & -.41 & -.21 & -.13 & -.20 & -.24 \\
\hline Organization & .56 & .45 & .12 & .21 & -.12 & .03 \\
\hline Impulsivity & -.28 & -.32 & -.16 & .13 & -.11 & -.03 \\
\hline Antisocial & -.52 & -.48 & -.45 & .11 & -.10 & -.15 \\
\hline Cleanliness & .34 & .26 & .07 & .20 & -.09 & -.02 \\
\hline Industriousness & .45 & .44 & .19 & .19 & .05 & .20 \\
\hline Laziness & -.57 & -.59 & -.12 & -.24 & -.07 & -.17 \\
\hline Appearance & .66 & .62 & .27 & .16 & -.06 & .14 \\
\hline Punctuality & .52 & .62 & .21 & 13 & .01 & .13 \\
\hline Formality & .30 & .40 & .17 & .14 & -.04 & .05 \\
\hline Responsibility & .33 & .38 & .39 & .12 & .14 & .11 \\
\hline
\end{tabular}

Note: $N$ ranged from 484 to 841 .

Table 3

Correlations with conscientiousness facet

\begin{tabular}{|c|c|c|c|c|c|c|c|c|c|c|c|c|c|}
\hline & \multicolumn{5}{|c|}{ Industriousness } & \multicolumn{4}{|c|}{ Orderliness } & \multicolumn{2}{|c|}{ Impulse control } & \multirow{2}{*}{$\begin{array}{l}\text { Comventional } \\
\text { Corventionality }\end{array}$} & \multirow{3}{*}{$\begin{array}{l}\text { Reliability } \\
\text { Reliability } \\
\text { CAC }\end{array}$} \\
\hline & Industrious & Purposeful & Dutiful & Efficiency & Orgarization & Order & Orderly & Rationality & Perfection & Impulse & Cautiousness & & \\
\hline & CAC & AHSC & ABSC & ABSC & ABSC & $C A C$ & ABSC & ABSC & ABSC & control $C A C$ & $\mathrm{ABSC}$ & CAC & \\
\hline He & $A 8$ & .66 & 64 & 61 & .60 & 57 & .68 & .30 & 51 & .55 & .30 & $A 0$ & 59 \\
\hline Avoid Wark & -34 & -.41 & -44 & $-A 4$ & -44 & -.13 & -.31 & -.31 & -.23 & -.41 & -.31 & -13 & -58 \\
\hline Organize & 25 & 37 & 25 & 32 & .32 & 56 & 55 & $-\omega \mathbb{2}$ & .37 & .24 & $\sigma 7$ & 25 & 30 \\
\hline Impulsivity & -31 & -25 & -37 & -21 & -2.9 & -.11 & -.21 & -.18 & -.16 & -.48 & -.60 & -11 & -.18 \\
\hline Antisocinl & -28 & -39 & -68 & -29 & -49 & -.24 & -48 & -.23 & -.42 & -.56 & -.31 & -32 & -52 \\
\hline Cemliness & 18 & .28 & 12 & 26 & .11 & .44 & 39 & -.01 & .22 & 04 & $-\infty \mathbb{2}$ & 26 & .12 \\
\hline Industrious & $A 6$ & .47 & 30 & A4 & .41 & .38 & .41 & .15 & 35 & 29 & .14 & 14 & 29 \\
\hline Laxiness & $-A 1$ & -72 & $-A S$ & -.75 & -.44 & -.53 & -.50 & -.48 & -36 & -.33 & -31 & -19 & -.41 \\
\hline Apperr mince & 28 & so & 55 & $A 4$ & .48 & 59 & .68 & .17 & .46 & .38 & aB & 27 & 52 \\
\hline Punctual & 28 & .49 & $A 8$ & $A 8$ & .46 & 37 & .46 & 32 & 31 & .45 & .16 & 31 & .47 \\
\hline Formality & 13 & 31 & 35 & 21 & .27 & .29 & .43 & .12 & .34 & .25 & 04 & 36 & .28 \\
\hline Responsibility & 15 & 35 & 37 & 32 & .38 & .19 & .28 & .23 & .20 & 29 & 04 & 16 & .42 \\
\hline
\end{tabular}

Note: $N=841$ for CAC and $N=484$ for AB5C.

ness. These questionnaires also differ in respect to format, with the AB5C using short phrases whereas the CAC uses adjectives. The former consists of items that can be considered behavioral (e.g., keep my checkbook balanced), which could lead to increased overlap with the behavioral factors. The remaining Big Five traits also were assessed using the AB5C.

Results and Discussion

All of the 11 behavioral factors were highly related to conscientiousness and not with the other Big Five traits, except for the antisocial and responsibility behavioral factors (see Table 2). These two facets were almost equally correlated with conscientiousness and agreeableness.

Extant facet scales of conscientiousness were correlated with the 11 behavioral factors to examine which components of conscientiousness were measured by each behavioral factor. Results suggest that each behavioral factor correlated significantly with previously identified facets of conscientiousness (Table 3). Five behavioral factors appear to best represent the five facets of conscientiousness previously identified (Jackson et al., 2009): BIC Avoid work best taps the reliability facet, the BIC organization factor corresponds to the orderfacet, the BIC impulsivity assesses the impulse control facet, BIC industriousness assesses the industriousness facet, and BIC formality best taps the conventionality facet. Interestingly, a number of behavioral factors represent blendsof these facets. The antisocial behavioral factor assesses both the impulse control and the reliability facets of conscientiousness whereas the cleanliness factor is related to both orderliness and reliability. Finally, some of these behavioral factors are not well differentiated by existing scales and are related to most of the previously identified facets of conscientiousness. For example, the punctuality and laziness factors are equally related to most facets of conscientiousness. These behaviors may best reflect the broad construct of conscientiousness and would be the ideal behaviors to include in shorter measures of conscientiousness behaviors that do not need to differentiate between the facets.

Study 3: Daily Diary Validation

One of the major limitations of most behavioral studies is that they are, in fact, not studies of behavior, but self-reports of behavior (Block, 1989; Furr, 2009). These retrospective reports may be marred by a number of biases, which, in turn, calls into question the accuracy of retrospective reports of behavior (Henry, Moffitt, Caspi, Langley, \& Silva, 1994). In contrast, some research has shown that retrospective reports can be quite valid predictors of actual behavior when used in the correct context, such as when predicting current behavior from recent retrospections (Gosling, Ko, Mannarelli, \& Morris, 2002). Since the BIC uses retrospective reports of behavior, we sought to validate how well the BIC predicts actual, real world behaviors. To test this idea, we assessed a subset of the BIC behaviors using a diary study where conscien- 
tious behaviors were cataloged daily. This allows a shorter time period between recall of behavior and the actual behavior, mitigating potential biases involved in recall. We predicted that the self-report measure of conscientious behaviors would be highly correlated with online assessments of behavior, giving ecological validity to the BIC.

\section{Method}

Participants

Sixty-three participants completed online daily diary assessments for two weeks as part of a class project. Nine participants completed less than six daily assessments and were dropped from analyses. A total of 54 participants ( 35 women, 19 men) completed daily diary studies for up to two weeks, with an average of 10 reports per participant. A total number of 552 daily diary reports were collected that assessed 27,600 possible instances of conscientious behavior.

\section{Measures}

At an initial training session, participants completed the 185item BIC developed in Study 1. This was administered to assess the frequency with which the participants performed conscientious behaviors. Reliability for the BIC was good (alpha $=.92$ ). The CAC (Jackson et al., 2009) was also administered, which measures five different facets of conscientiousness as described in Study 2.

\section{Procedure}

After the training session, participants were instructed to visit an online site each night before they went to bed. Every night the website listed 45 behaviors pulled from the BIC (items can be found in Appendix A). These items comprise a shortened form of the 11 behavioral factors of the BIC. The 45 items chosen were the items with the largest factor loadings for each behavioral factor reported in Study 1 and consisted of enough items from each factor to ensure adequate reliability. Participants were asked to identify whether or not they performed each behavior during the day by checking yes or no.

\section{Results and Discussion}

Online assessed behaviors were aggregated daily into a composite for each individual, creating an index for the average number of conscientious behaviors each person performed daily throughout the two weeks. A large number of conscientious behaviors were enacted (or unconscientious behaviors were not enacted) per day with an average of 26 out of 45 possible behavioral manifestations. The average number of average daily conscientious behaviors across individuals ranged from 14.40 conscientious behaviors per day to 37.35 conscientious behaviors per day $(S D=4.76)$.

These average online conscientious behaviors were compared to the BIC questionnaire that participants completed in the initial session to assess whether the BIC captures real world behavior. The total score from the BIC questionnaire correlated with the total score of the online conscientiousness behavioral composite exceedingly well $(r=.49, p<$ $.01)$, suggesting that the BIC re.ects actual behavior frequency rather than biased judgments of behavior. Similarly, the total score of online conscientiousness behaviors correlated with the overall CAC measure of conscientiousness $(r=.37, p$
$<.01)$, suggesting that these real world behaviors are associated with the trait of conscientiousness. The lower order facets of conscientiousness also correlated with daily behaviors (average $r=.34$ ), with the facet of impulse control correlating the strongest with average daily conscientious behavior $(r=.44, p<.01)$. The 11 behavioral factors, rather than overall BIC score, also were associated with average daily conscientious behavior. The average correlations between the BIC factors and daily behavior factors (i.e., BIC organization with online assessed organizing behaviors) were good (average $r$ $=.36$, all above .25), suggesting that each behavioral factor assesses the desired target behavior.

These findings suggest that self-reported retrospective ratings of conscientious behaviors were strongly related to behaviors assessed daily using a diary method. The crossmethod overlap between self-reported behavior and actual real world behavior is similar in magnitude to past findings where behavior was assessed online in a laboratory setting and reported on retrospectively (Borkenau \& Ostendorf, 1987; Gosling et al., 1998). This suggests that reports of past behavior are at least partially valid, mitigating a criticism often applied to self-reports of behavior (e.g., Block, 1989).

\section{Overall Discussion}

This study sought to identify the behavioral component of conscientiousness. Our primary goal was to be broad in our approach and to identify a relatively large pool of behaviors that, though of great breadth, are all still associated with the domain of conscientiousness. The resulting behaviors represented coherent themes of goal achievement and self-control, broadly construed. Conscientious individuals are clean and tidy, work hard, follow the rules of society and social decorum, think before acting, and are organized. For example, conscientious people tend to write down important dates, comb their hair, polish their shoes, stand up straight, and scrub floors. People who are less conscientious exceed their credit limit, watch more television, cancel plans, curse, oversleep, and break promises.

The effort to map out a model of conscientious behaviors was predicated on several assumptions and goals. Our primary assumption was that a trait was not solely a collection of behaviors but, rather, a composite of thoughts, feelings, and behaviors. Traditional measures of personality traits include items related to cognitions and affect in addition to behavioral items (Pytlik Zillig et al., 2002; Werner \& Pervin, 1986). However, the content of any given personality inventory is normally compiled unsystematically, at least in reference to the domains of thoughts, feelings, and behaviors. For example, the AB5C measure includes a number of items for conscientiousness that reflect more cognitive appraisals or feelings, rather than objective behaviors (e.g., "Set high standards for myself and others;" "Am not bothered by messy people;" "Demand quality;" Goldberg, 1999). This series of studies was the first attempt to systematically identify just the behavioral aspect of conscientiousness.

From this view, behavior is only one part of what constitutes a personality trait. Individuals can have the same latent trait level of conscientiousness but differ in frequency and type of their behavior. Behavior is therefore conceptualized as a lower order manifestation of a personality trait and can be used 
as a state like variable (Roberts \& Jackson, 2008). In this hierarchical model, a trait is conceptualized as real, existing as neurobiological structures (Depue \& Lenzenweger, 2005; Roberts \& Jackson, 2008; Tellegen, 1991) with traits at the highest and most broad level of analysis and the constituent thoughts, feelings, and behaviors that make up personality at the lowest level (Roberts \& Pomerantz, 2004). That is not to say that behavior is solely determined through traits. Behavior has multiple determinants, such as other traits, motives, goals, interests, and situational factors (Ahadi \& Diener, 1989; Funder, 2001). Thus, behavior is not equated with personality traits. However, the study of behavior is useful for both the description of the trait and for uncovering the processes that link traits to important outcomes (Fleeson \& Noftle, 2008; Furr, 2009).

Furthermore, the behavioral approach taken here offers another way to investigate the lower-order structure of conscientiousness. Replicating past research (Peabody \& De Raad, 2002; Perugini \& Gallucci, 1997; Roberts et al., 2005; Saucier \& Ostendorf, 1999), the four-factor solution suggests that responsibility, order, impulse control, and laziness are the most important constructs related to conscientiousness. Extracting more than four factors revealed a number of other interesting candidates for the facets of conscientiousness such as formality, appearance, and punctuality. The facet of formality did not emerge until later in the behavioral hierarchy, despite being strongly related to conventionality, which is considered one of the main components of conscientiousness (Jackson et al., 2009; Roberts et al., 2004). This most likely occurs because conventionality is mainly an attitudinal facet that is manifest as a set of beliefs rather than as behaviors (e.g., the MPQ's Traditionalism scale uses beliefs as the stem to most items). This is in contrast to cleanliness in which a direct behavioral outcome of the trait is readily apparent. This highlights the need to develop measures that assess the cognitive and affective components of traits in addition to the behavioral domain.

Despite a number of advantages that behavioral inquiry affords, a number of limitations occur when behavior is the level of analysis (Furr, 2009). Our study was no exception and a number of future avenues of research are needed. First, the behaviors identified in the BIC are obviously not a complete list of conscientiousness behaviors. The behaviors listed in the BIC make up but a subset of the behaviors that conscientious individuals perform daily. Moreover, while the BIC attempted to be applicable to most age groups, it is likely that different behaviors emerge when one becomes a parent or retires. A second limitation is that the behaviors were self-reported. Though validated through a daily diary study, observational studies, observer reports and methods that use behavioral residue of conscientious behaviors would be useful to further validate the behaviors identified in this study (e.g., Back et al., 2009; Vazire, 2006).

Despite the shortcomings, the BIC is nonetheless advantageous for a number of reasons that suggest further research. First, it provides a starting point for future studies that validate conscientious behaviors in the real world. In the quest to find out what conscientious people do it is somewhat impractical to study a vast number of behaviors across many locations. Instead, the BIC offers a way to focus on a particular subset of behaviors that appear to be related to conscientiousness. Secondly, to the extent that personality questionnaires already measure behavior, thoughts and feelings, it is useful to examine how the content and utility of the trait may differ depending on what content area is salient. Feelings associated with conscientiousness (e.g., feeling guilty for neglecting work) are likely to overlap with the structure found here but not completely. Measures that highlight emotional components over behavioral components exist (e.g., Watson, Clark, \& Tellegen, 1988) but an advanced investigation of the pros and cons of a behavioral versus an emotional (or cognitive) measure for a specific trait has yet to emerge. This is partly due to the fact that no current measurement system separates a trait into the constituent components of behavior, emotion and cognitions.

In summary, this study identified what conscientious people do in their daily lives. Despite emerging from the end of the decade purportedly devoted to studying behavior (Azar, 1999), a number of commentators suggest that the study of behavior is still neglected in social and personality psychology (Agnew, Carlston, Graziano, \& Kelly, 2010; Baumeister, Vohs, \& Funder, 2007; Furr, 2009). Much work has focused on the cognitive and emotional basis of human functioning, but little has focused on overt behavior (Furr, 2009). We suggest that the approach used here to uncover the Behavioral Indicators of Conscientiousness is a meaningful step to better understand behavior in the context of personality psychology.

\begin{tabular}{|c|c|c|c|}
\hline \multicolumn{4}{|l|}{ Appendix A } \\
\hline \# Item & BIC-11 & BIC-4 & $r$ \\
\hline \multicolumn{3}{|c|}{1 Play sick to avoid doing something $(r) \mathrm{W}^{*}$} & -.27 \\
\hline 2 Oversleep for class or work $(r)$ & W & I & -.37 \\
\hline 3 Miss a meeting $(r)$ & $\mathrm{W}^{*}$ & I & -.26 \\
\hline $\begin{array}{l}4 \text { Call in sick to work because of } \\
\text { being too tired to get up }(r)\end{array}$ & & -.22 \\
\hline 5 Blow off work $(r)$ & $\mathrm{W}^{*}$ & & -.33 \\
\hline 6 Call in sick to work when not sick $(r)$ & $W^{*}$ & I & -.24 \\
\hline \multicolumn{3}{|c|}{7 Make a grocery list before going to the store $\mathrm{O}$} & .26 \\
\hline 8 Label drawers in my office & $\mathrm{O}$ & & .24 \\
\hline \multicolumn{2}{|c|}{9 Used a planner to schedule the day's events $O$} & II & .31 \\
\hline 10 Cross off items from my to do list & $\mathrm{O}^{*}$ & & .34 \\
\hline 11 Make an itinerary & $\mathrm{O}$ & & .28 \\
\hline 12 File papers in a desk drawer & $\mathrm{O}$ & & .30 \\
\hline 13 Organize my closet & $\mathrm{O}$ & & .23 \\
\hline 14 Make lists & $\mathrm{O}^{*}$ & & .35 \\
\hline 15 Save receipts & $\mathrm{O}$ & & .21 \\
\hline $\begin{array}{l}16 \text { Use a calendar or date book to } \\
\text { plan my activities }\end{array}$ & $\mathrm{O}^{*}$ & & .34 \\
\hline 17 Keep my desk or work area clean & $\mathrm{O}$ & II & .42 \\
\hline 18 File financial documents & $\mathrm{O}$ & & .28 \\
\hline $\begin{array}{l}19 \text { Organize work files and } \\
\text { materials in a systematic manner }\end{array}$ & $\mathrm{O}$ & II & .38 \\
\hline \multicolumn{4}{|l|}{20 Use a file system for important papers $\mathrm{O}^{*}$} \\
\hline $\begin{array}{l}21 \text { Organize books by height, } \\
\text { author, or genre }\end{array}$ & $\mathrm{O}$ & & .22 \\
\hline 22 Write in a date book & $\mathrm{O}$ & II & .26 \\
\hline 23 Alphabetize or organize recipes & $\mathrm{O}$ & & .19 \\
\hline \multicolumn{3}{|c|}{24 Set a timeline for getting a project done $\mathrm{O}$} & .49 \\
\hline 25 Spend more money than I should $(r)$ & $\mathrm{I} \mathrm{C}^{*}$ & IV & -.17 \\
\hline \multicolumn{3}{|c|}{26 Cancel or switch plans at the last minute IC } & -.27 \\
\hline 27 Do things spur of the moment $(r)$ & $\mathrm{IC}^{*}$ & IV & -.34 \\
\hline 28 Buy something on a whim $(r)$ & $\mathrm{IC}^{*}$ & IV & -.18 \\
\hline $\begin{array}{l}29 \text { Go shopping with list and only } \\
\text { buy things on the list }\end{array}$ & \multicolumn{2}{|c|}{ buy things on the list } & .25 \\
\hline 30 Purchase something spontaneously & (r) $\mathrm{IC}^{*}$ & IV & -.09 \\
\hline 31 Spend more money than I have $(r)$ & IC & IV & -.22 \\
\hline 32 Break daily routine $(\mathrm{r})$ & IC & & -.40 \\
\hline 33 Go somewhere on a moent's notice & (r) IC & IV & -.21 \\
\hline
\end{tabular}


Appendix A (continued)

\# Item

34 Drink alcohol during work hours $(r)$

$\begin{array}{ccc}\text { BIC-11 } & \text { BIC-4 } & r \\ \mathrm{~A}^{*} & & -.22 \\ \mathrm{~A} & & -.27\end{array}$

35 Wear clothes with stains or

holes in them to work $(r)$

36 Belch in public $(r)$

37 Break the law $(r)$

38 Lie to authority figures (r)

39 Say exactly what I feel (r)

40 Smash something when angry or frustrated $(r)$ A IV $\quad-.21$

41 Use slang terms or cursing

when speaking to my boss $(r)$

42 Spit in public $(r)$

43 Wear clothes with stains in them $(r)$

44 Break rules in games and sports $(r)$

45 Yell at another driver $(r)$

46 Go out and party despite having

things to do $(r)$

47 Steal things from a store $(r)$

48 Shout at a stranger in public $(r)$

49 Deceive others about my real age $(r)$

50 Throw garbage out of the car window $(r)$ A

51 Use slang terms or curse $(r)$

A --.27

$\mathrm{A}--.16$

$\mathrm{A}^{*}-.30$

A -.27

$-.24$

$\mathrm{A}--.22$

A $\quad-.30$

A -.34

$\mathrm{A}^{*} \quad-.11$

A -.35

53 Shout or make noise in public on a whim $(r)$

54 Wear clothes with holes in them $(r) \quad$ A

55 Commit a crime $(r)$

A -.16

$\mathrm{A}--.20$

A $\quad-.25$

$\begin{array}{ll}\mathrm{A} & -.17\end{array}$

A $\quad-.22$

A $\quad$ IV -21

(r) A $\quad-.27$

$-.27$

$-.36$

$-.25$

56 Try to get something without paying for it $(r) \mathrm{A}$

57 Scrub the floors in the house/apartment $C^{*}$

58 Clean my toilet

59 Clean the inside of the microwave oven C

60 Clean the inside of an oven

61 Dust the rooms in my home

62 Clean the bathroom

63 Scrub shower .oors and walls

64 Wash my car

65 Clean the windows in my house

66 Iron c

67 Dust in hard-to-reach areas in my house $C^{*}$

68 Do laundry

69 Work or study long hours

70 Work until I am physically exhausted I

71 Work or study on a Friday or

Saturday evening

72 Finish a set amount of work

before relaxing

73 Volunteer to do things at work

74 Persist at tasks after meeting

setbacks or failures

75 Work extra hard on a project to

make sure that it is done right

76 Complete the projects I start

in timely fashion

77 Work overtime

78 Bypass a difficult task $(r)$

79 Put off work until the last minute $(r) \quad$ L

80 Have trouble making a decision $(r)$

81 Lose something important in the

clutter of my living quarters $(r)$

82 Have trouble deciding what to

do with my day $(r)$

83 Have trouble deciding where to eat $(r) \quad \mathrm{L}$

84 Sit and do nothing $(r)$

85 Give up on a problem $(r)$

86 Leave dirty clothes on the floor $(r)$

87 Forgot to write down important notes $(r) \mathrm{L}$

88 Slouch $(r)$

89 Watch TV or go on the internet

instead of taking care of responsibilities $(r)$
Appendix A (continued)

\# Item

90 Wash dishes after a meal

91 Make my bed

92 Clean up immediately after a meal $\quad \begin{array}{ll}\mathrm{AP}^{*} & .31 \\ \mathrm{AP}^{*} & \end{array}$

93 Allow trash to overflow from a container $(r)$ AP

94 Put so much food in my mouth AP

that some fell out $(r)$

95 Throw away garbage

96 Share domestic duties

97 Clean bedroom

AP $\quad .21$

98 Clean desk surfaces (no piles of papers) AP

99 Clean up right after company leaves

100 Clean around the house/apartment

101 Share household chores

$A P$

102 Fold my clothes right after they are washed AP .31

103 Get to appointments on time $\quad P^{*} \quad .32$

104 Allow extra time for getting lost

$\mathrm{P}$

when going to new places

105 Miss appointments $(r)$

106 Am the first person to show up

$\begin{array}{lll}P^{*} & \text { I } & -.44\end{array}$

for work or a class

107 Complete assignments on time

108 Turn in assignments late $(r)$

109 Leave for work at the exact time

$\mathrm{P} \quad .30$

I had planned

110 Show up for work more than

5 min early

111 Miss the bus $(r)$

that are not part of my job

112 Get to work on time

113 Forget about an appointment $(r)$

114 Forget meetings $(r)$

115 Return phone calls and emails

116 Late for a meeting $(r)$

117 Keep up with required work

118 Sit with a straight back

119 Call someone Ms., Mr., Mrs., Sir, etc.

120 Uphold cultural traditions

121 Stand with a straight back and neck

122 Make use of someone's formal title

123 Uphold family traditions

124 Cheat on tests $(r)$

125 Break promises $(r)$

126 Say please and thank you

127 Lie to a significant other $(r)$

128 Steal things from a friend $(r)$

129 Lie to my family $(r)$

130 Keep my promises

131 Repay favors

132 Hold the door for people

133 Borrow something and lose it,

$\begin{array}{ll}\mathrm{P} & .37\end{array}$

$\mathrm{P}-\quad-.43$

$P^{*}$

.24

break it, or never return it $(r)$

134 Leave unfinished food sitting out $(r) \quad$ G $\quad-.31$

135 Tell a child a rule for proper etiquette $\quad G \quad .23$

136 Get a haircut on a regular schedule $\quad$ G $\quad .20$

137 Steal thing from work $(r) \quad$ G $\quad-.27$

138 Exceed my credit limit $(r)$

$-.25$

(continued on next page)

139 Back out on appointments $(r) \quad$ G $\quad$ I $\quad-.36$

140 Miss a bill payment $(r) \quad$ G $\quad-.24$

141 Comb hair $\quad$ G $\quad .21$

142 Change order in a restaurant after ordering $(r) \mathrm{G} \quad-.17$

143 Lose office supplies $(r) \quad$ G $\quad-.37$

144 Come into restaurants knowing $\quad$ G

what I will order

145 Take wrong materials to class or work $(r) \mathrm{G}$

146 Fulfill an obligation to someone $\quad$ G $\quad$ I $\quad .30$

147 Tell lies $(r)$

5 .

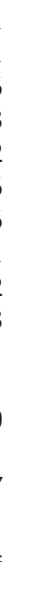

7

\begin{tabular}{l}
.36 \\
.17 \\
7 \\
.06 \\
.35 \\
0 \\
\hline 7
\end{tabular}


Appendix A (continued)

\# Item

148 Correct incorrect change

BIC-11 BIC-4

149 Wait until a sale before buying a product G

150 Dress up for an important occasion G

151 Go to church regularly

G

152 Say something I later strongly regretted $(r) \mathrm{G}$

153 Donate time to a volunteer

activity/organization

154 Continue a problem-solving

strategy even after it has failed

155 Polish my shoes

156 Fold underwear

157 Clean the inside of my car

158 Brush lint or dust off someone

else's clothes

159 Forget materials for class/work ( $r$ )

160 Read manual before operating a

purchase

161 Speak highly of my country

162 Double-check my work

163 Waffle when asked to commit

to a group projects $(r)$

164 Leave assignments at home $(r)$

165 Wear shoes with holes in them $(r)$

166 Use someone else's stuff

without asking $(r)$

167 Put a napkin in my lap

168 Read the directions completely

before assembling a new purchase

169 Wear wrinkled clothes $(r)$

170 Miss a meeting with a friend $(r)$

171 Break rules in games $(r)$

172 Proofread my writing

173 Measure exact amount when cooking

174 Need to borrow pen, pencils, or

paper for class $(r)$

175 Keep track of people's birthdays

176 Leave dishes in the sink $(r)$

177 Cheat on my taxes $(r)$

178 File old bills/receipts

179 Talk with my mouth full $(r)$

180 Pay bills on time

181 Keep pens and pencils in

separate drawers

182 Vacuum my house/apartment/room

183 Cook meals for my family

184 Ignore employer's suggestions $(r)$

185 Eat until I felt sick $(r)$

Note: $\mathrm{BIC}-11=11$ factor scale $\mathrm{W}=$ avoid work, $\mathrm{O}=$ organization, $\mathrm{IC}=$ impulsivity, $\mathrm{A}=$ antisocial, $\mathrm{C}=$ cleanliness, $\mathrm{L}=$ laziness, $\mathrm{I}=$ industriousness, $\mathrm{P}=$ punctual, $\mathrm{AP}=$ appearance, $\mathrm{F}=$ formality, $\mathrm{R}$ = responsibility, $\mathrm{G}=$ general conscientious behavior, $\mathrm{BIC}-4=4$ factor scale. I = responsibility, II = organization, III = laziness, IV = impulsivity, $\mathrm{r}=$ item correlation with conscientiousness from Study 2, *=used in BIC short form in daily diary study.

References

Ahadi, S., \& Diener, E. (1989). Multiple determinants and effect size. Journal of Personality and Social Psychology 56: 398-406.

Agnew, C.R., D.E. Carlston, W.G. Graziano \& J.R. Kelly (Eds.). (2010). Then a Miracle Occurs: Focusing on Behavior in Social Psychological Theory and Research. New York: Oxford University Press.

Asendorpf, J.B., R. Banse \& D. Mücke (2002). Double dissociation between implicit and explicit personality self-concept: the case of shy behavior. Journal of Personality and Social Psychology 83: 380-393.
Azar, B. (1999). Decade of Behavior moves forward. APA Monitor 30: 199.

Back, M.D., S.C. Schmukle \& B. Egloff (2006). Who is late and who is early? Big Five personality factors and punctuality in attending psychological experiments. Journal of Research in Personality 40: 841-848.

Back, M.D., S.C. Schmukle \& B. Egloff (2009). Predicting actual behavior from the explicit and implicit self-concept of personality. Journal of Personality and Social Psychology 97: 533-548.

Baumeister, R.F., K.D. Vohs \& D.C. Funder (2007). Psychology as the science of self-reports and finger movements. Whatever happened to actual behavior? Perspectives on Psychological Science 2: 396-403.

Block, J. (1989). Critique of the act frequency approach to personality. Journal of Personality and Social Psychology 56: 234-245.

Borkenau, P., N. Mauer, R. Riemann, F.M. Spinath \& A. Angleitner (2004). Thin slices of behavior as cues of personality and intelligence. Journal of Personality and Social Psychology 86: 599-614.

Borkenau, P., \& B. Muller (1992). Inferring act frequencies and traits from behavior observations. Journal of Personality 60: 553-573.

Borkenau, P., \& F. Ostendorf (1987). Retrospective estimates of act frequencies: how accurately do they reflect reality? Journal of Personality and Social Psychology 52: 626-638.

Botwin, M.D., \& D.M. Buss (1989). The structure of act data: Is the .ve factor model of personality recaptured? Journal of Personality and Social Psychology 56: 988-1,001.

Buss, D.M., \& K.H. Craik (1980). The frequency concept of disposition: Dominance and prototypically dominant acts. Journal of Personality 48: 379-392.

Buss, D.M., \& K.H. Craik (1983). The act frequency approach to personality. Psychological Review 90: 105-126.

Church, A.T., M.S. Katigbak, L.G. Miramontes, A.M. del Prado \& H.F. Cabrera (2007). Culture and the behavioral manifestations of traits: an application of the act frequency approach. European Journal of Personality 21: 389-417.

Costa, P.T., Jr., R.R. McCrae \& D.A. Dye (1991). Facet scales for agreeableness and conscientiousness: a revision of the NEO personality inventory. Personality and Individual Differences 12: 887-898.

Depue, R.A., \& M.F. Lenzenweger (2005). A neurobehavioral dimensional model of personality disturbance. In: Major Theories of Personality Disorder (2nd ed., pp. 1-63). Guilford Press.

DeYoung, C.G., L.C. Quilty \& J.B. Peterson (2007). Between facets and domains: 10 Aspects of the Big Five. Journal of Personality and Social Psychology 93: 880-896.

Epstein, S. (1979). The stability of behavior: I. On predicting most of the people much of the time. Journal of Personality and Social Psychology 37: 1,097-1,126.

Fast, L.A., \& D.C. Funder (2008). Personality as manifest in word use: correlations with self-report, acquaintance-report, and behavior. Journal of Personality and Social Psychology 94: 334-346.

Fleeson, W. (2007). Situation-based contingencies underlying traitcontent manifestation in behavior. Journal of Personality 75: 825-862.

Fleeson, W., \& E.E. Noftle (2008). Where does personality have its influence? A supermatrix of consistency concepts. Journal of Personality $76: 1,355-1,385$.

Funder, D.C. (1991). Global traits: a neo-Allportian approach to personality. Psychological Science 2: 31-38.

Funder, D.C. (2001). Personality. Annual Review of Psychology 52: 197221.

Funder, D.C. (2006). Towards a resolution of the personality triad: Persons, situations, and behaviors. Journal of Research in Personality 40: 21-34.

Funder, D.C. (2009). Persons, behaviors and situations: An agenda for personality psychology in the postwar era. Journal of Research in Personality 43: 120-126.

Funder, D.C., \& C.D. Sneed (1993). Behavioral manifestations of personality: An ecological approach to judgmental accuracy. Journal of Personality and Social Psychology 64: 479-490.

Furr, R.M. (2009). Personality psychology as a truly behavioral science. European Journal of Personality, 23: 369-401.

Furr, R.M., \& D.C. Funder (2007). Behavioral observation. In: R. Rob- 
ins, C. Fraley, \& R. Krueger (Eds.), Handbook of Research Methods in Personality Psychology (pp. 273-291). New York: Guilford Press.

Goldberg, L.R. (1999). A broad-bandwidth, public domain, personality inventory measuring the lower-level facets of several Fivefactor models. In: I. Mervielde, I. Deary, F. De Fruyt, \& F. Ostendorf (Eds.). Personality Psychology in Europe, volume 7 (pp. 7-28). Tilburg, Netherlands: Tilburg University Press.

Goldberg, L.R. (2006). Doing it all bass-ackwards: The development of hierarchical factor structures from the top down. Journal of Research in Personality 40: 347-358.

Gosling, S.D., O.P. John, K.H. Craik \& R.W. Robins (1998). Do people know how they behave? Self-reported act frequencies compared with on-line codings by observers. Journal of Personality and Social Psychology 74: 1,337-1,349.

Gosling, S.D., S.J. Ko, T. Mannarelli \& M.E. Morris (2002). A Room with a cue: judgments of personality based on of.ces and bedrooms. Journal of Personality and Social Psychology 82: 379-398.

Heller, D., J. Komar \& W.B. Lee (2007). The dynamics of personality states, goals and well being. Personality and Social Psychology Bulletin 33: 898-910.

Henry, B., T.E. Moffitt, A. Caspi, J. Langley \& P.A. Silva (1994). On the "remembrance of things past": a longitudinal evaluation of the retrospective method. Psychological Assessment 6: 92-101.

Hong, R.Y., S.V. Paunonen \& H.P. Slade (2008). Big Five personality factors and the prediction of behavior: A multitrait-multimethod approach. Personality and Individual Differences 45: 160-166.

Hough, L.M., \& D.S. Ones (2001). The structure, measurement, validity, and use of personality variables in industrial, work, and organizational psychology. In: N. Anderson, D.S. Ones, H.K. Sinangil, \& C. Viswesvaran (Eds.). Handbook of Industrial Work and Organizational Psychology, volume 1, Personnel Psychology (pp. 233-277). London: Sage.

Jackson, J.J., T. Bogg, K. Walton, D. Wood, P.D. Harms, J.L., LodiSmith, et al. (2009). Not all conscientiousness scales change alike: a multi-method, multi-sample study of age differences in the facets of conscientiousness. Journal of Personality and Social Psychology 96: 446-459.

John, O.P., \& S. Srivastava (1999). The Big Five trait taxonomy; history, measurement, and theoretical perspectives. In: L.A. Pervin \& O.P. John (Eds.). Handbook of Personality Theory and Research, volume 2 (pp. 102-138). New York: Guilford Press.

Judge, T.A., C.A. Higgins, C.J. Thoresen \& M.R. Barrick (1999). The big five personality traits, general mental ability, and career success across the life span. Personnel Psychology 52: 621-652.

Kern, M.L., \& H.S. Friedman (2008). Do conscientious individuals live longer? A quantitative review. Health Psychology 27: 505-512.

Lodi-Smith, J.L., J.J. Jackson, T. Bogg, K. Walton, D. Wood, P.D. Harms, et al. (2010). Mechanisms of health: education and healthrelated behaviors partially mediate the relationship between conscientiousness and self-reported physical health. Psychology and Health 25: 305-319.

MacCann, C., Duckworth, A. L., \& Roberts, R. D. (2009). Empirical identi.cation of the major facets of conscientiousness. Learning and Individual Differences 19: 451-458.

Markey, P.M., C.N. Markey \& B.J. Tinsley (2004). Children's behavioral manifestations of the five-factor model of personality. Personality and Social Psychology Bulletin 30: 423-432.

Markon, K.E., R.F. Krueger \& D. Watson (2005). Delineating the structure of normal and abnormal personality: an integrative hierarchical approach. Journal of Personality and Social Psychology 88: 139-157. Mehl, M.R., S.D. Gosling \& J.W. Pennebaker (2006). Personality in its natural habitat: manifestations and implicit folk theories of personality in daily life. Journal of Personality and Social Psychology 90: 862-877.

Nave, C.S., R.A. Sherman \& D.C. Funder (2008). Beyond self-report in the study of hedonic and eudaimonic well-being: correlations with acquaintance reports, clinician judgments and directly observed social behavior. Journal of Research in Personality 42: 643-659.
Ozer, D., \& V. Benet-Martínez (2006). Personality and the prediction of consequential outcomes. Annual Review of Psychology 57: 401-421.

Paunonen, S.V. (2003). Big Five factors of personality and replicated predictions of behavior. Journal of Personality and Social Psychology 84: 411-422.

Paunonen, S.V., \& D.N. Jackson (1996). The Jackson personality inventory and the Five-Factor model of personality. Journal of Research in Personality 30: 42-59.

Peabody, D., \& B. De Raad (2002). The substantive nature of psycholexical personality factors: a comparison across languages. Journal of Personality and Social Psychology 83: 983-997.

Perugini, M., \& M. Gallucci (1997). A hierarchical faceted model of the Big Five. European Journal of Personality 11: 279-301.

Pytlik Zillig, L.M., S.H. Hemenover \& R.A. Dienstbier (2002). What do we assess when we assess a Big 5 trait? A content analysis of the affective, behavioral and cognitive processes represented in the Big 5 personality inventories. Personality $\mathcal{E}$ Social Psychology Bulletin 28: 847-858.

Roberts, B.W., T. Bogg, K.E. Walton, O.S. Chernyshenko \& S.E. Stark (2004). A lexical investigation of the lower-order structure of conscientiousness. Journal of Research in Personality 38: 164-178.

Roberts, B.W., O. Chernyshenko, S. Stark \& L. Goldberg (2005). The structure of conscientiousness: an empirical investigation based on seven major personality questionnaires. Personnel Psychology 58: 103-139.

Roberts, B.W., \& J.J. Jackson (2008). Sociogenomic personality psychology. Journal of Personality 76: 1,523-1,544.

Roberts, B.W., J.J. Jackson, J.V. Fayard, G. Edmonds \& J. Meints (2009). Conscientiousness. In: M. Leary \& R. Hoyle (Eds.), Handbook of Individual Differences in Social Behavior (pp. 369-381). New York: Guilford.

Roberts, B.W., N. Kuncel, R. Shiner, A. Caspi \& L.R. Goldberg (2007). The power of personality: the comparative validity of personality traits, socio-economic status, and cognitive ability for predicting important life outcomes. Perspectives in Psychological Science 2: 313-345.

Roberts, B.W., \& E.M. Pomerantz (2004). On traits, situations, and their integration: a developmental perspective. Personality and Social Psychology Review 8: 402-416.

Saucier, G., \& F. Ostendorf (1999). Hierarchical subcomponents of the Big Five personality factors: a cross-language replication. Journal of Personality and Social Psychology 76: 613-627.

Spain, J.S., L.G. Eaton \& D.C. Funder (2000). Perspectives on personality: the relative accuracy of self vs. Others for the prediction of behavior and emotion. Journal of Personality 68: 837-867.

Tackett, J.L., L.C. Quilty, M. Sellbom, N. Rector \& R.M. Bagby (2008). Additional evidence for a quantitative hierarchical model of the mood and anxiety disorders for DSM-V: the context of personality structure. Journal of Abnormal Psychology 117: 812-825.

Tellegen, A. (1991). Personality traits: Issues of definition, evidence, and assessment. In: D. Cicchetti \& W.M. Grove (Eds.). Thinking Clearly about Psychology: Essays in Honor of Paul E. Meehl, Personality and Psychopathology (Vol. 2, pp. 10-35). Minneapolis, Minn.: University of Minnesota Press.

Vazire, S. (2006). Informant reports: a cheap, fast, and easy method for personality assessment. Journal of Research in Personality 40: 472-481.

Vazire, S., \& M.R. Mehl (2008). Knowing me, knowing you: The accuracy and unique predictive validity of self and other ratings of daily behavior. Journal of Personality and Social Psychology 95: 1,202-1,216.

Watson, D., L.A. Clark \& A. Tellegen (1988). Development and validation of brief measures of positive and negative affect: the PANAS scale. Journal of Personality and Social Psychology 54: 1,063-1,070.

Werner, P.D., \& L.A. Pervin (1986). The content of personality inventory items. Journal of Personality \& Social Psychology 51: 622-628.

Wu, K.D., \& L.A. Clark (2003). Relations between personality traits and self-reports of daily behavior. Journal of Research in Personality 37: 231-256. 